Results: The PsA cohort consisted of 5,275 patients, 53.2\% females with mean age of $51.66 \pm 15.41$. The control group consisted of 21,011 subjects matched for age and sex. In relation to the control group, the PSA cohort had a higher SES $(25.1 \%$ vs $23.4 \%$, $\mathrm{p}<0.0001)$, higher tobacco use $(42.2 \%$ vs.39.6\% $\mathrm{p}<0.0001)$ and obesity (33.5\% vs $25.8 \%, p<0.0001)$. The study group had a statistically significant higher incidence of diabetes (33.8\% vs $26.2 \%, \mathrm{p}<0.0001)$, IHD (10.3\% vs $8.6 \%, \mathrm{p}<0.0001)$, CHF (2.2\% vs $1.6 \%, p=0.004)$, hypertension ( $30.1 \%$ vs $26.2 \%, p<0.0001)$, CVATIA ( $4.6 \%$ vs $3.9 \%, p=0.024)$ and vascular disease $(3.7 \%$ vs $3.0 \%, p=0.005)$. There were 62 patients (1.2\%) diagnosed with VTE in the PsA group as opposed to 176 patients $(0.8 \%)$ in the control group $(\mathrm{p}=0.023, \mathrm{HR}=1.397, \mathrm{Cl} 1.05-1.87)$. The mean age of patients diagnosed with VTE was higher in the PsA group relative to controls $(64.90 \pm 13.20$ vs $51.54 \pm 15.41$, respectively, $\mathrm{p}<0.0001)$, with higher age, $\mathrm{BMI}>30$, cancer, IHD, vascular disease, and previous VTE found to be associated with VTE in the PSA group relative to controls in both univariate and multivariate analyses. The higher prevalence of VTE in PsA patients relative to controls did not remain statistically significant in multivariate analysis following adjustment for risk factors. Within the PsA group, patients with VTE were more often of older age and with past history of VTE. Both CDMARD and bDMARD were not associated with increased risk of VTE among PsA patients.

Conclusion: The prevalence of VTE was higher in PSA group compared to the general population, but after adjustment for comorbidities and risk factors, it no longer remained statistically significant. Among PsA patients, age and previous history of VTE were associated with increased risk of VTE. Addressing VTE risk in the management of patients with PsA is recommended especially in the era of Janus kinase inhibitors.

Disclosure of Interests: None declared

DOI: 10.1136/annrheumdis-2021-eular.1811

\section{POS0148 PREGNANT WOMEN WITH PSORIASIS AND PSORIATIC ARTHRITIS: A SYSTEMATIC REVIEW AND META-ANALYSIS}

W. Xie ${ }^{1}$, H. Huang ${ }^{1}$, Z. Zhang ${ }^{1}{ }^{1}$ Peking University First Hospital, Department of Rheumatology and Clinical Immunology, Beijing, China

Background: Psoriasis and psoriatic arthritis (PsA) are inflammatory diseases that affect women in their reproductive years. The evidence regarding the pregnancy outcomes in psoriasis and PSA is more limited and conflicting, to a large extent, confusing our knowledge on this topic.

Objectives: We aim to investigate whether maternal psoriasis and PsA are associated with adverse pregnancy outcomes.

Methods: We searched multiple electronic databases from inception to 3 August 2020 , and reference lists of selected articles. Observational studies reporting at least one pregnancy outcomes in women with psoriasis or PsA with a comparator of general population or healthy subjects were included. Data were pooled by random-effects models (DerSimonian and Laird method) and expressed as odds ratio (OR) and $95 \%$ confidence interval $(\mathrm{Cl})$.

Results: Overall, 16 studies were included in the meta-analysis. The pooled analyses showed pregnant women with psoriatic diseases have significantly higher risk of adverse maternal outcomes compared with general population (caesarean delivery: 1.33 (1.17-1.52); preterm birth: 1.32 (1.15-1.52); (pre)eclampsia: 1.28 (1.14-1.43); gestational diabetes: 1.19 (1.10-1.30); gestational hypertension: 1.30 (1.18-1.44) (Figure 1). However, no statistically increased risks of fetal complications were observed in women with psoriatic diseases (small for gestational age: 1.02 (0.93-1.11); low birth weight: 1.15 (0.93-1.42); congenital malformations: 1.03 (0.93-1.14); Apgar score <7: 1.07 (0.81-1.39); neonatal mortality: 1.13 (0.90-1.43); stillbirth: 1.19 (0.95-1.50)). Subgroup analysis found similar results in women with either psoriasis or PsA regarding maternal outcomes, but the magnitude of risk estimates seems to be greater in PsA. Conclusion: Pregnant women with psoriasis and PSA have excess risk of adverse maternal events, with seemingly higher risk in women with PsA, but not adverse neonatal events. Close monitoring of the mothers' clinical status before and during pregnancy are decidedly required in daily practice.

\begin{tabular}{|c|c|c|c|}
\hline Pregnant outcomes & No. Study & Odds ratio $(95 \% \mathrm{Cl})$ & $1^{2}$ \\
\hline $\begin{array}{l}\text { Maternal outcomes } \\
\text { Cacuran didfivery }\end{array}$ & & & \\
\hline 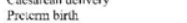 & 10 & $1.32(1.15-1.52)$ & $77.5 \%$ \\
\hline Preeclampsia or eclampsia & 8 & $1.28(1.14-1.43)$ & $51.2 \%$ \\
\hline $\begin{array}{l}\text { Gestational diabetes } \\
\text { Gestrtional hyyertension }\end{array}$ & 5 & $1.19(1.10-1.30)$ & $0.0 \%$ \\
\hline $\begin{array}{l}\text { Gestational hypertension } \\
\text { Spontaneous abortion }\end{array}$ & ${ }_{4}^{4}$ & $\begin{array}{l}1.30(1.188-1.44) \\
1.440 .95-217\end{array}$ & $11.6 \%$ \\
\hline $\begin{array}{l}\text { Spontanenus abotition } \\
\text { Premature rupture of membranes }\end{array}$ & ${ }_{3}^{4}$ & $\begin{array}{l}1.44(0.959-2.17) \\
1.48(0.89-2.46)\end{array}$ & $\begin{array}{l}77.3 \% \\
649 \%\end{array}$ \\
\hline Ante-or postpertum hemorthage & 3 & $1.08(0.74-1.60)$ & $88.9 \%$ \\
\hline $\begin{array}{l}\text { Neonatal outcomes } \\
\text { Small for pestational age }\end{array}$ & & & \\
\hline 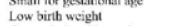 & 5 & & $\begin{array}{l}28.6 \% \\
.000 \%\end{array}$ \\
\hline genual malfornations & 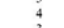 & $\begin{array}{l}1.03(0.93-1.14) \\
1.03\end{array}$ & $0.0 \%$ \\
\hline gar score 4 & & $1.07(0.81-1.39)$ & $47.4 \%$ \\
\hline onatal mortality & & $1.13(0.90-1.43)$ & $0.0 \%$ \\
\hline & & $1.19(0.95-1.50)$ & $21.8 \%$ \\
\hline
\end{tabular}

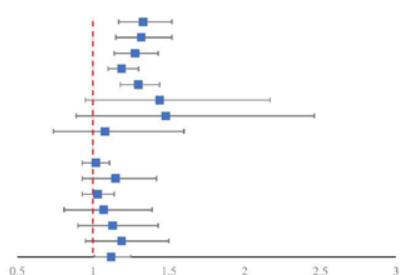

Figure 1. Forest plots of the odds ratio for the risk of adverse pregnancy outcomes in patients with psoriatic diseases.
Disclosure of Interests: None declared

DOI: 10.1136/annrheumdis-2021-eular.2283

\begin{tabular}{l|l}
\hline POS0149 & MUSCULOSKELETAL PAIN IN PATIENTS WITH \\
PSORIASIS AND THE INFLUENCE ON HEALTH- \\
RELATED QUALITY OF LIFE: RESULTS FROM A \\
DANISH POPULATION-BASED SURVEY
\end{tabular}

S. Kamp Felbo ${ }^{1,2}$, L. Terslev ${ }^{1,2}$, I. J. Sørensen ${ }^{3}$, L. Skov ${ }^{2,4}$, C. Zachariae ${ }^{2,4}$, M. Østergaard ${ }^{1,2} .{ }^{1}$ Rigshospitalet, Copenhagen Center for Arthritis Research, Center for Rheumatology and Spine Diseases, Glostrup, Denmark; ${ }^{2}$ University of Copenhagen, Department of Clinical Medicine, Copenhagen, Denmark; ${ }^{3}$ Rigshospitalet, Center for Rheumatology and Spine Diseases, Copenhagen, Denmark; ${ }^{4}$ Herlev and Gentofte Hospitals, Department of Dermatology and Allergy, Gentofte, Denmark

Background: Psoriasis (PsO) impacts health-related quality of life (HRQoL) The impact of musculoskeletal (MSK) pain in patients without diagnosed psoriatic arthritis (PsA) (1) is poorly understood.

Objectives: To assess the pattern of MSK pain in patients with PsO, and its influence on important patient-reported outcomes.

Methods: A nationwide survey of patients with PsO and PsA, covering skin and MSK symptoms, healthcare contacts, self-assessed disease severity, treatment satisfaction, HRQoL (including Dermatology Life Quality Index (DLQI) and European Quality of life-5 Dimensions (EQ5D)) and disability. Respondents were grouped according to MSK pain as shown in Table 1. 'PsO previous pain' was combined with 'PsO no pain ever' (labeled 'PsO no pain now') for some analyses and with 'PsO pain now' (labeled 'PsO pain ever') for others.

Results: 561 respondents with PsO completed the questionnaire. Population and subgroup demographics, clinical PsA/PsO features and HRQoL measures are shown in Table 1. Patients in 'PsO pain now' had poorer HRQoL (higher DLQI, lower EQ5D) compared to 'PsO no pain now', and similar to patients with PsA. Patients with PsA assessed their PsO severity higher than patients with ' $\mathrm{PsO}$ pain ever' and 'PsO no pain ever' (median (interquartile range) 2 (2-3), 2 (1-3) and $2(1-2)$ on a five-level scale, respectively). PsO treatment satisfaction (five-level scale) was lower for 'PsO pain ever' (3 (3-4)) than for 'PsO no pain ever' (4 (3-4), $\mathrm{p}=0.03$ ). Figure 1 shows contacts to dermatologists and rheumatologists, where $72 \%$ of patients in 'PsO pain ever' had never been examined by a rheumatologist. Time from symptom debut to diagnosis was 1.5 (1-3) years for $\mathrm{PsO}$ and 7.5 (1.5-12.5) for PsA.

Table 1. Population and subgroup characteristics

\begin{tabular}{|c|c|c|c|c|c|c|c|c|}
\hline DEMOGRAPHICS & All & $\begin{array}{l}\text { PsO no } \\
\text { pain ever }\end{array}$ & $\begin{array}{c}\mathrm{PsO} \\
\text { previous } \\
\text { pain }\end{array}$ & $\begin{array}{c}\text { PsO pain } \\
\text { now }\end{array}$ & PsA & & $\mathrm{p}$-value ${ }^{\star}$ & \\
\hline $\mathrm{N}$ & 561 & 178 & 104 & 130 & 108 & & & \\
\hline Male & 212 (38\%) & 79 (44\%) & $34(33 \%)$ & $36(28 \%)$ & $40(37 \%)$ & & 0.02 & \\
\hline Age (years) & $58(43-68)$ & $58(43-68)$ & $\begin{array}{c}56 \\
(42-63)\end{array}$ & $\begin{array}{c}53 \\
\quad(43-63)\end{array}$ & $\begin{array}{c}58 \\
(48-68)\end{array}$ & & 0.05 & \\
\hline Body Mass Index & $27(24-32)$ & $26(23-30)$ & $\begin{array}{c}28 \\
(24-32)\end{array}$ & $\begin{array}{c}29 \\
(25-33)\end{array}$ & $\begin{array}{c}28 \\
(24-33)\end{array}$ & & 0.01 & \\
\hline $\begin{array}{l}\text { No current } \\
\text { occupation }^{1}\end{array}$ & $119(21 \%)$ & $20(11 \%)$ & $23(22 \%)$ & $34(26 \%)$ & $35(32 \%)$ & & $<0.001$ & \\
\hline $\begin{array}{l}\text { PsO/PsA } \\
\text { FEATURES }\end{array}$ & All & $\begin{array}{l}\text { 1. PsO no } \\
\text { pain } \\
\text { ever }\end{array}$ & 2. $\mathrm{PsO} p$ & pain ever & 3. PsA & 1 vs. 2 & 1 vs. 3 & 2 vs. 3 \\
\hline $\mathrm{N}$ & 561 & 178 & & 34 & 108 & & & \\
\hline BSA (\%) & $1(1-2)$ & $1(1-2)$ & $1(1$ & 1-2) & $2(1-2)$ & 0.10 & $<0.001$ & 0.01 \\
\hline Nail psoriasis & $134(24 \%)$ & $27(15 \%)$ & $50(2$ & $21 \%)$ & $46(48 \%)$ & 0.13 & $<0.001$ & $<0.001$ \\
\hline ‘Dactylitis' 2a & $80(14 \%)$ & $2(1 \%)$ & $34(1$ & $15 \%)$ & $40(42 \%)$ & $<0.001$ & $<0.001$ & $<0.001$ \\
\hline 'Enthesitis' 2b & $74(13 \%)$ & $4(2 \%)$ & $30(1$ & $13 \%)$ & $39(41 \%)$ & $<0.001$ & $<0.001<$ & $<0.001$ \\
\hline $\begin{array}{l}\text { QUALITY OF } \\
\text { LIFE AND } \\
\text { DISABILITY }\end{array}$ & All & $\begin{array}{l}\text { 1. PsO no } \\
\text { pain } \\
\text { now }\end{array}$ & 2. $\mathrm{PsO} p$ & pain now & 3. PsA & 1 vs. 2 & 1 vs. 3 & 2 vs. 3 \\
\hline $\mathrm{N}$ & 561 & 282 & & 30 & 108 & & & \\
\hline DLQI score (0-30) & $2(1-5)$ & $1(1-4)$ & $2(1$ & $1-5)$ & $2(1-6)$ & 0.001 & 0.04 & 0.52 \\
\hline EQ5D index $(0-1)$ & $\begin{array}{l}0.797 \\
(0.691- \\
0.859)\end{array}$ & $\begin{array}{c}0.859 \\
(0.768- \\
1)\end{array}$ & $\begin{array}{r}0.7 \\
(0.67\end{array}$ & $\begin{array}{l}732 \\
9-0.859)\end{array}$ & $\begin{array}{c}0.702 \\
(0.598- \\
0.802)\end{array}$ & $<0.001$ & $<0.001$ & 0.53 \\
\hline HAQ score $(0-3)$ & $\begin{array}{l}0.63 \\
(0-1.25)\end{array}$ & & $0.50(0$ & $0-0.88)$ & $\begin{array}{c}0.88 \\
(0.13- \\
1.38)\end{array}$ & & & 0.03 \\
\hline
\end{tabular}

Numbers are numbers (\%) (binary data), median (interquartile range) (continuous data).BSA Body Surface Area (palm-size areas of the body with psoriasis). DLQI: Dermatology life quality index (higher scores $=$ higher impact of disease). EQ5D: European Quality of life-5 Dimensions -5 Domain (higher scores = better health state). HAQ: Health assessment questionnaire. PsA: Psoriatic arthritis. PsO: Psoriasis. ${ }^{*}$ Multiple groups: Chi-square test/ KruskalWallis test. Pairwise: Fishers exact test/Mann-Whitney U test1. I.e. work/studies/retirement 2. a. "Swollen entire finger or toe" b. "Tender or swollen tendon". 

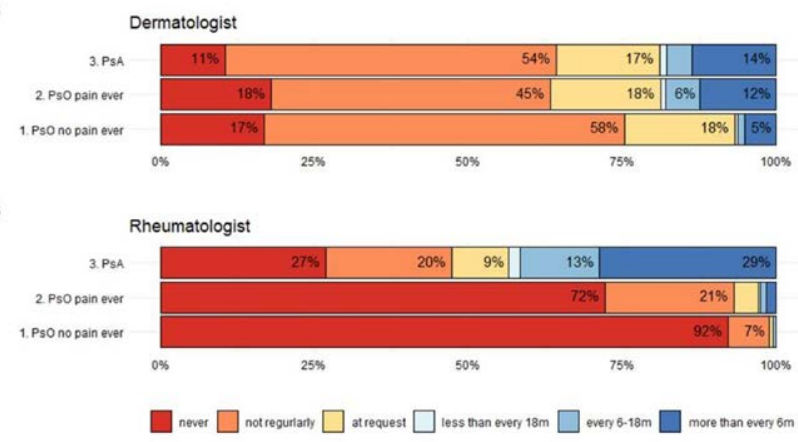

Figure 1. Contacts to specialists by subgroup

Conclusion: Patients with $\mathrm{PsO}$ and MSK pain have decreased HRQoL compared to patients with PsO without MSK pain, to a similar degree as patients with PsA. Many have never been examined by a rheumatologist, demonstrating an unmet need for adequate evaluation of these patients.

REFERENCES:

[1] Lebwohl MG et al. Patient perspectives in the management of psoriasis: results from the population-based Multinational Assessment of Psoriasis and Psoriatic Arthritis Survey. J Am Acad Dermatol. 2014

Acknowledgements: The authors acknowledge the participants who contributed to this study. The study was financially supported by Amgen/Celgene. The Danish Rheumatism Association, The Danish Psoriasis Research Foundation and The Capital Region of Denmark have supported the work of SKF. The sponsors had no influence on study design, data analysis or manuscript preparation. Disclosure of Interests: Sara Kamp Felbo Grant/research support from: Celgene, Lene Terslev Speakers bureau: AbbVie, Janssen, Roche, Novartis, Pfizer, MSD, BMS, Inge Juul Sørensen: None declared, Lone Skov Speakers bureau: AbbVie, Eli Lilly, Novartis, and LEO Pharma, Consultant of: AbbVie, Janssen Cilag, Novartis, Eli Lilly, LEO Pharma, UCB, Almirall, Bristol-Myers Squibb, and Sanofi., Grant/research support from: Novartis, Sanofi, Bristol-Myers Squibb, Janssen Cilag, and LEO Pharma., Claus Zachariae Speakers bureau: Eli Lilly, Jansen Cilag, Novartis, Abbvie, Takeda, Amgen, Almirall, CSL, UCB, Regeneron, MSD, and Leo Pharma, Consultant of: Eli Lilly, Jansen Cilag, Novartis, Abbvie, Takeda, Amgen, Almirall, CSL, UCB, Regeneron, MSD, and Leo Pharma, Mikkel Østergaard Speakers bureau: AbbVie, BMS, Boehringer-Ingelheim, Celgene, Eli-Lilly, Hospira, Janssen, Merck, Novartis, Novo, Orion, Pfizer, Regeneron, Roche, Sandoz, Sanofi and UCB, Consultant of: AbbVie, BMS, Boehringer-Ingelheim, Celgene, Eli-Lilly, Hospira, Janssen, Merck, Novartis, Novo, Orion, Pfizer, Regeneron, Roche, Sandoz, Sanofi and UCB, Grant/research support from: AbbVie, BMS, Boehringer-Ingelheim, Celgene, Eli-Lilly, Hospira, Janssen, Merck, Novartis, Novo, Orion, Pfizer, Regeneron, Roche, Sandoz, Sanofi and UCB DOI: 10.1136/annrheumdis-2021-eular.1053

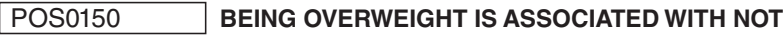 REACHING LOW DISEASE ACTIVITY IN WOMEN BUT NOT MEN WITH PSORIATIC ARTHRITIS}

M. Mulder ${ }^{1}$, M. Wenink ${ }^{1}$, J. Vriezekolk ${ }^{1}$. Sint Maartenskliniek, Rheumatology, Nijmegen, Netherlands

Background: Disease manifestations and outcomes of psoriatic arthritis (PsA) seem to differ between sexes. Gaining knowledge about the underlying mechanisms of these differences between men and women is important to optimize treatment strategies, especially given that women seem to less often reach low disease activity (LDA) treatment targets ${ }^{1,2}$.

Objectives: To assess sex differences in disease activity parameters and health-related quality of life in PsA, and to assess whether determinants associated with not reaching treatment target differed between men and women.
Methods: A cross-sectional study was conducted, using data from a routine practice cohort of 855 patients with PsA, that were all tightly monitored and treated. Gender differences with respect to Psoriatic Arthritis Disease Activity Score (PASDAS), skin/nail disease, SF12-PCS, SF12-MCS, inflammatory backpain (IBP), and demographics were assessed. Multivariate analyses were used to examine determinants associated with not reaching PASDAS $\leq 3.2$ (LDA) in men and women.

Results: Women had worse scores for - among others- swollen and tender joints, CRP, enthesitis, and function (all $\mathrm{P}<0.001$ ). Higher PASDAS scores in women were found than in men, mean $3.5(S D=1.5)$ vs $2.7(S D=1.5), p<0.001$ Likewise, women were more often not at PASDAS treatment target (OR = 2.03, $P<0.001)$. Besides being female, also the presence of nail disease and IBP, a higher number of DMARDs used in the past or current number of DMARDs used, and a higher Body Mass Index (BMI) were associated with not reaching the treatment target in the overall sample. No differences in current medication use was found between the sexes. Table 1 shows that for women, but not men, BMI was associated with not reaching PASDAS $\leq 3.2$ (BMI 25-30: $\mathrm{OR}=3.6, \mathrm{P}<0.001$; $\mathrm{BMI} 30-35$ : $\mathrm{OR}=2.41, \mathrm{P}=0.023$; $\mathrm{BMI}>35$ : $\mathrm{OR}=2.45, \mathrm{P}=0.002$ )

Conclusion: Women with PsA in a tightly monitored and treated setting have more severe disease than men. This is demonstrated by worse scores for women in both subjective and objective disease activity measures, in addition to women less often reaching the treatment target. Notably, being overweight is associated with not reaching the treatment target in women, but not men.

\section{RENCES:}

[1] Theander E, Husmark T, Alenius GM, Larsson PT, Teleman A, Geijer M, et al. Early psoriatic arthritis: short symptom duration, male gender and preserved physical functioning at presentation predict favourable outcome at 5-year follow-up. Results from the Swedish Early Psoriatic Arthritis Registe (SwePsA). Ann Rheum Dis. 2014;73(2):407-13.

[2] Orbai AM, Perin J, Gorlier C, Coates LC, Kiltz U, Leung YY, et al. Determinants of Patient-Reported Psoriatic Arthritis Impact of Disease: An Analysis of the Association with Gender in 458 Patients from 14 Countries. Arthritis Care Res (Hoboken). 2019.

Table 1. Final multivariate logistic regression model of determinants associated with not reaching PASDAS target stratified for gender

\begin{tabular}{|c|c|c|c|c|}
\hline \multirow[b]{2}{*}{ Variable } & \multicolumn{2}{|c|}{ Men $(N=465)$} & \multicolumn{2}{|c|}{ Women $(\mathrm{N}=390)$} \\
\hline & OR $(95 \% \mathrm{Cl})$ & P-value & OR $(95 \% \mathrm{Cl})$ & P-value \\
\hline BMI $25-30 \mathrm{~kg} / \mathrm{m}^{2}$ (ref: <25) & & & $\begin{array}{c}3.6 \\
(1.86-6.99)\end{array}$ & $<0.001$ \\
\hline BMI $30-35 \mathrm{~kg} / \mathrm{m}^{2}$ (ref: <25) & & & $\begin{array}{c}2.41 \\
(1.12-5.14)\end{array}$ & 0.023 \\
\hline $\mathrm{BMI}>35 \mathrm{~kg} / \mathrm{m}^{2}($ ref: $<25)$ & & & $\begin{array}{c}2.45 \\
(1.40-4.28)\end{array}$ & 0.002 \\
\hline Presence of nail disease & & & $\begin{array}{c}1.57 \\
(0.97-2.55)\end{array}$ & 0.066 \\
\hline Presence of IBP & $\begin{array}{c}2.75 \\
(1.13-6.70)\end{array}$ & 0.026 & $\begin{array}{c}3.22 \\
(1.52-6.85)\end{array}$ & 0.002 \\
\hline MCS (SF12) & $\begin{array}{c}0.93 \\
(0.90-0.95)\end{array}$ & $<0.001$ & $\begin{array}{c}0.96 \\
(0.94-0.98)\end{array}$ & 0.001 \\
\hline cDMARD use (ref: no DMARD) & $\begin{array}{c}1.16 \\
(0.58-2.31)\end{array}$ & 0.671 & & \\
\hline bDMARD use (ref: no DMARD) & $\begin{array}{c}0.49 \\
(0.23-1.02)\end{array}$ & 0.057 & & \\
\hline Number of DMARDs history & $\begin{array}{c}1.36 \\
(1.17-1.59)\end{array}$ & $<0.001$ & $\begin{array}{c}1.13 \\
(1.02-1.25)\end{array}$ & 0.015 \\
\hline Number of DMARDs current & $\begin{array}{c}1.90 \\
(1.11-3.24)\end{array}$ & 0.018 & & \\
\hline
\end{tabular}

* A P-value of $<0.05$ is considered significant. PASDAS = psoriatic arthritis disease activity score; $\mathrm{BMI}=$ body mass index; IBP = inflammatory backpain; SF12-MCS = short form-12 mental component scale; cDMARD = conventional DMARD; bDMARD = biological disease-mod ifying antirheumatic drug.

Disclosure of Interests: None declared

DOI: 10.1136/annrheumdis-2021-eular.1530 